\section{Diallel analysis in agronomic traits of Jatropha}

\section{Paulo Eduardo Teodoro ${ }^{1}$, Erina Vitório Rodrigues² ${ }^{2}$ Leonardo de Azevedo Peixoto ${ }^{1}$, Bruno Galvêas Laviola ${ }^{2}$ and Leonardo Lopes Bhering $^{1^{*}}$}

\begin{abstract}
The objectives of this study were to estimate the general and specific combining ability of the parents, and to verify the existence of maternal effect and inbreeding depression in Jatropha. The experiment was carried out from 2010 to 2015, in the municipality of Planaltina, Distrito Federal. The following traits were evaluated: plant height, stem diameter, canopy projection between the row, canopy projection on the row, number of branches, mass of one hundred grains, and grain yield. Cytoplasmic effects and effects of female parent nuclear genes were observed for all traits. Dominance effects were predominant in the genetic control of all traits. Genotypes 107 and 190 were the superior parents for the reduction of the size, and for the increase of grain yield. No inbreeding depression was observed for grain yield. The most promising crosses for the conduction of segregating populations and increment in grain yield were $190 \times 107,107 \times 190$ and $259 \times 107$.
\end{abstract}

Key words: Jatropha curcas $L$, reciprocal effect, inbreeding depression, quantitative genetics.

\section{INTRODUCTION}

Jatropha curcas L. has unisexual, insect-pollinated monoeceious flowers, and shows protandry, however, hermaphroditic, self-pollinated flowers may occasionally occur (Kumar and Sharma 2008). It is a species of great importance due to its multiple use (Laviola et al. 2013). It was first introduced in Brazil to be used as hedges, and for small-scale oil production (Rosado et al. 2010). However, faced with the need for alternative sources of cleaner energy, and to the high energy demand required by the population, the interest in Jatropha cultivation has increased, since it is a promising culture to be used in biofuel production (Ong et al. 2013, Spinelli et al. 2014, Laosatit et al. 2017). Despite this, there are few studies on the breeding of this culture, since this species is under domestication.

Thus, aiming at the implementation of a breeding program of Jatropha in Brazil, researches have focused on the implementation of germplasm bank (Laviola et al. 2012a); on studies on genetic diversity (Rosado et al. 2010, Wen et al. 2010); and on estimates of genetic parameters (Laviola et al. 2012a, Santana et al. 2013). Estimates of genetic parameters are important in the orientation of breeding programs, since they support the selection process, and serve as reference for the understanding of the genetic structure of the population, in order to use it in a more accurate way in the breeding program (Rosado et al. 2010).
Crop Breeding and Applied Biotechnology 17: 259-265, 2017 Brazilian Society of Plant Breeding. Printed in Brazil http://dx.doi.org/10.1590/198470332017v17n3a39 


\section{PE Teodoro et al.}

Concomitantly with these studies, parents selection is crucial. This step must be carried out very carefully, since it does not ensure the obtainment of progenies with high genetic potential when it is based only on desirable agronomic traits. Thus, diallel crosses is a technique that assists the choice of parents, aiming at improving accuracy in selection. This methodology selects superior parents based on the genotypic values, on the general combining ability (GCA), and on the specific combining ability (Cruz et al. 2012).

Diallel analyses estimate parameters that are useful in parents selection for hybridization and in the understanding of the genetic effects involved in the determination of the traits. Among the commonly used methods, the model of Griffing (1956) stands out for estimating GCA and SCA. The first refers to the performance of a parent in a series of crosses, and is associated with additive genetic effects; the second refers to the performance of specific hybrid combinations in relation to the parents means, and is related to the dominance and epistasis effects and several types of gene interactions. Moreover, they inform about the importance of reciprocal and maternal effects, and about the capitalization of heterosis (Cruz et al. 2012).

Although diallel analyses are useful in the understanding of the genetic basis of traits and in decision-making regarding the parents and the promising hybrid combinations, there are few reports related to this technique in Jatropha (Biabani et al. 2012, Santana et al. 2013, Islam et al. 2013). Therefore, the objectives of this study were to estimate the general combining ability (GCA) and the specific combining ability (SCA) of the parents used in the crosses, and to verify the existence of maternal effect and of inbreeding depression.

\section{MATERIAL AND METHODS}

\section{Experimental area}

The experiment was carried out from 2010 to 2015, in the municipality of Planaltina, Distrito Federal (lat $15^{\circ} 35^{\prime} 30^{\prime \prime}$ $\mathrm{S}$, long $47^{\circ} 42^{\prime} 30^{\prime \prime} \mathrm{W}$, alt $1007 \mathrm{~m}$ asl). The climate is tropical with dry winter and rainy summer (Aw), with average annual temperature of $21{ }^{\circ} \mathrm{C}$, relative humidity of $68 \%$, and average rainfall of $1,100 \mathrm{~mm} /$ year. The soil is classified as Oxisol, with high clay content. The soil of the experimental area was corrected with limestone to raise the base saturation to $60 \%$. At planting, $400 \mathrm{~g}$ per plant of superphosphate were applied to the soil. After planting, $200 \mathrm{~g}$ per plant of 20:00:20 fertilizer formulation were applied, which were divided into three applications at 30, 60 and 90 days. The experiment was carried out without irrigation. Management practices were based on Rosado et al. (2010).

\section{Experimental design and traits evaluated}

Crosses were carried out in March, 2010, in a complete diallel scheme, totaling three selfings and six hybridizations. The experiment consisted of randomized blocks design, with five replications, and three plants per plot, spaced $4 \times 2$ $\mathrm{m}$ apart. Three genotypes were used in the crosses, which were selected in the germplasm bank, with the following characteristics: small size (CNPAE-107), high grain yield (CNPAE-190), and resistance to powdery mildew (CNPAE-259). Only three parents were chosen, since they represent all the genetic variability for the most important agronomic traits in jatropha in Brazil. The seeds of the crosses obtained $\left(F_{1} s\right)$ were sown in January 2011.

The following traits were evaluated: plant height $(\mathrm{PH}, \mathrm{m})$, stem diameter $(\mathrm{SD}, \mathrm{mm})$, canopy projection between rows (CPB, $m)$, canopy projection on the row (CPR, $m$ ), number of branches (NB), mass of a hundred grains (MHG, $g$ ), and grain yield $\left(\mathrm{GY}, \mathrm{g}_{\text {plant }}{ }^{-1}\right)$. The traits $\mathrm{PH}, \mathrm{CPB}, \mathrm{CPR}$, and NB were evaluated in the third year after sowing (2013); SD was measured in the first year (2011); MHG was measured in the fourth year (2014); and GY was evaluated in the fifth year (2015).

\section{Genetic-statistics analysis}

Initially, analyses of variance were carried out for each trait, according to the model: $Y_{i j}=\mu+g_{i}+b_{j}+\varepsilon_{i j}$ in which $Y_{i j}$ is the valued measured in the plot, analyzed for the $i$-th genotype, in the $j$-th block; $\mu$ is the overall mean; $g_{i}$ is the effect of the $i$-th genotype, considered as fixed $(i=1,2, \ldots, 9) ; b_{j}$ is the effect of the $j$-th block, considered as fixed $(j=1,2, \ldots$, 5); $e_{i j}$ is the effect of the random error associated with the ij observation with NID $\left(0, \sigma^{2}\right)$.

The quadratic component associated with the genotypic effects $\left(\phi_{\mathrm{g}}\right)$, with the environmental variance $\left(\hat{\sigma}_{e}^{2}\right)$; as well as 
the quadratic component associated with phenotypic effects $\left(\phi_{\mathrm{f}}\right)$, coefficient of genotypic determination $\left(\mathrm{H}^{2}\right)$, selective accuracy (Ac), coefficient of genotypic variation $\left(\mathrm{CV}_{\mathrm{g}}\right)$, coefficient of environmental variation (CVe), coefficient of relative variation $(\mathrm{CV} r)$, given by the ratio $\mathrm{CV}_{\mathrm{g}} / \mathrm{CV}_{\mathrm{e}}$ were obtained by analysis of variance. Subsequently, means clustering was carried out for each trait by using the Scott-Knott test.

Diallel analyses were carried out according to the model 1 of Griffing (1956):

$Y_{i j}=\mu+g_{i}+g_{j}+s_{i j}+r_{i j}+\varepsilon_{i j}$, in which $\mathrm{Y}_{\mathrm{ij}}$ is the mean value of the hybrid combination $(\mathrm{i} \neq \mathrm{j})$ or of the parent $(\mathrm{i}=\mathrm{j}) ; \mu$ is the general mean; $g_{i}$ and $g_{j}$ are the effects of the general combining ability of the $i$-th genotype or of the j-th parent $(i, j=1,2$ and 3$) ; s_{i j}$ is the effect of the specific combining ability for crosses between parents $i$ and $j ; r_{i j}$ is the reciprocal effect that measures the difference provided by parent $\mathrm{i}$ or $\mathrm{j}$ when used as male or female in the cross $\mathrm{ij}$; and $\mathrm{e}_{\mathrm{ij}}$ is the effect of the mean error associated with the ij observation with $\sim \operatorname{NID}\left(0, \sigma^{2}\right)$.

In this model, the $g_{i}$ effect was defined as: i ranging from 1 to number of genotypes (nine), since the diallel analysis was performed using the experimental unit mean (three plants per experimental unit). Also, it was considered $s_{i j}=s_{j i j}, r_{i j}$ $=-r_{\mathrm{ji}}$ and $r_{\mathrm{ii}}=0$. From this model, estimates of general combining ability (GCA) and of specific combining ability (SCA), reciprocal effects, and quadratic components $(\Phi)$ were obtained. All statistical analyses were carried out using the Genes software (Cruz 2013).

\section{RESULTS AND DISCUSSION}

\section{Genetic parameters}

The estimates of genetic variability $\left(\phi_{\mathrm{g}}\right)$ were higher than the estimates of environmental variance $\left(\hat{\sigma}_{e}^{2}\right)$ for all traits (Table 1), which reveals predominance of genetic effect. Estimates of coefficient of genotypic determination $\left(\mathrm{H}^{2}\right)$ obtained for all traits can be considered high (> 70\%), since they result from polygenic traits, which are governed by several genes of little effect on the phenotype. The square root of $\mathrm{H}^{2}$ reflects in the selective accuracy statistics (Ac), which indicates the quality of the information and of the procedures used in the prediction of genetic values. This parameter is associated with the precision of the selection, and refers to the correlation between predicted genetic values and actual genetic values of the individuals (Resende and Duarte 2007). Thus, the genetic values predicted for the population are reliable due to the high estimates of Ac for all traits.

For Cruz et al. (2012), the experimental precision is high when the estimates of the coefficient of environmental variation $\left(\mathrm{CV}_{\mathrm{e}}\right)$ are lower than $20 \%$, as in the present study, except for $\mathrm{GY}\left(\mathrm{CV}_{\mathrm{e}}=28 \%\right.$ ). Borges et al. (2014) found $\mathrm{CV}_{\mathrm{e}}$ of 29, 39 and $39 \%$ for GY in the first, second and third year of Jatropha production, which was similar to the values observed in this study. Estimates of $\mathrm{CV}_{\mathrm{e}}$ obtained in this work are in accordance with those reported in other studies on Jatropha (Laviola et al. 2012b, Laviola et al. 2013, Bhering et al. 2013, Borges et al. 2014, Ramos et al. 2014, Spinelli et al. 2015).

The coefficient of genetic variation $\left(\mathrm{CV}_{\mathrm{g}}\right)$ quantifies the proportion of the genetic variability available for selection (Cruz et al. 2012). The ratio between this parameter and $\mathrm{CV}_{\mathrm{e}}$ results in the coefficient of relative variation $\left(\mathrm{CV}_{\mathrm{r}}\right)$. Thus, the values obtained from $\mathrm{CV}_{\mathrm{g}}$ provided $\mathrm{CV}_{\mathrm{r}}$ superior to 1 for all traits indicates favorable situation for the selection of

Table 1. Estimates of genetic parameters for the traits plant height (PH), stem diameter (SD), canopy projection between rows (CPB), canopy projection on the row (CPR), mass of one hundred grains (MHG), and grain yield (GY) evaluated in nine Jatropha genotypes

\begin{tabular}{lccccccc}
\hline Parameters & PH & SD & CPB & CPR & NB & MHG \\
\hline$\phi_{\mathrm{g}}$ & 0.137 & 17.71 & 0.22 & 0.05 & 11.13 & 34.81 \\
$\hat{\sigma}_{e}^{2}$ & 0.003 & 1.88 & 0.01 & 0.01 & 3.81 & 3.35 \\
$\phi_{\mathrm{f}}$ & 0.140 & 19.59 & 0.23 & 0.06 & 14.94 & 38.16 & 204375.55 \\
$\mathrm{H}^{2}(\%)$ & 98 & 90 & 97 & 87 & 75 & 91 & 91 \\
$\mathrm{Ac}(\%)$ & 99 & 95 & 98 & 93 & 86 & 96 \\
$\mathrm{CV}$ & $(\%)$ & 15 & 6 & 18 & 11 & 9624.38 & 9 \\
$\mathrm{CV}_{\mathrm{e}}(\%)$ & 5 & 4 & 7 & 9 & 20 & 6 \\
$\mathrm{CV}_{\mathrm{r}}(\%)$ & 3 & 1 & 3 & 1 & 1 & 28 \\
\hline
\end{tabular}

$\phi_{\mathrm{g}:}$ quadratic component associated with genotypic effects; $\hat{\sigma}_{e}^{2}$ environmental variance; $\phi_{\mathrm{f}}$ : quadratic component associated with phenotypic effects; $\mathrm{H}^{2}$ : coefficient of genotypic determination; $\mathrm{Ac}$ : selective accuracy; $\mathrm{CV}_{\mathrm{g}}$ : coefficient of genotypic variation; $\mathrm{CV}_{\mathrm{e}}$ : coefficient of environmental variation; $\mathrm{CV}_{\mathrm{r}}$ : coefficient of relative variation. 


\section{PE Teodoro et al.}

superior genotypes in the population to be obtained from crosses.

The genetic variability reported in this study indicates the possibility of obtaining gains with selection in populations, and proves that the chosen genotypes are contrasting among each other, as observed by Rosado et al. (2010), at molecular level.

\section{Diallel analysis}

Diallel analysis made it possible to know the performance of the parents among each other, their hybrid combinations, and the nature of the reciprocal effect (Table 2). Estimates of general and specific combining ability, besides the reciprocal effect, were significant by the F-test for all traits, except for GCA for canopy projection on the row (CPR). These results indicate the existence of additive genetic effects, non-additive genetic effects, and/or cytoplasmic effects of female genitor involved in the control of the traits.

However, when evaluating the quadratic components $(\Phi)$, dominance effects $\left(\Phi_{s c}\right)$ were superior in the genetic control of all traits, which indicates the existence of differences in the gene compositions of the parents used in the study. When higher estimates of $\Phi$ sc are observed in relation to the others, the parents are divergent for most of the loci in dominance, and the heterotic manifestations exhibited by these crosses may result from genetic complementation between the loci that control the evaluated traits.

Therefore, these results suggest that methods that prioritize the capitalization of heterosis must be used in order to

Table 2. Mean squares and quadratic components $(\Phi)$ obtained by diallel analysis for the traits plant height (PH), stem diameter (SD), canopy projection between rows (CPB), canopy projection on the row (CPR), mass of one hundred grains (MHG), and grain yield (GY) evaluated in nine Jatropha genotypes

\begin{tabular}{llccccccc}
\hline SV & df & PH & SD & CPB & CPR & NB & MHG & GY \\
\hline Treatment & 8 & $0.55^{+}$ & $147.11^{+}$ & $0.70^{+}$ & $0.637^{+}$ & $176.32^{+}$ & $462.84^{+}$ & $1549525.65^{+}$ \\
GCA & 2 & $0.40^{+}$ & $373.17^{+}$ & $0.04^{+}$ & 0.003 & $117.20^{+}$ & $756.98^{+}$ & $2193597.26^{+}$ \\
SCA & 3 & $0.94^{+}$ & $90.03^{+}$ & $1.23^{+}$ & $0.799^{+}$ & $210.57^{+}$ & $546.34^{+}$ & $2154437.05^{+}$ \\
Reciprocal & 3 & $0.25^{+}$ & $53.49^{+}$ & $0.61^{+}$ & $0.898^{+}$ & $181.49^{+}$ & $183.26^{+}$ & $515233.17^{+}$ \\
Residue & 32 & 0.02 & 9.39 & 0.03 & 0.039 & 19.03 & 16.73 & 88121.92 \\
\hline$\Phi_{\text {gc }}$ & - & 0.01 & 12.13 & 0.00 & 0.0 & 3.27 & 24.67 & 70182.51 \\
$\Phi_{\text {sc }}$ & - & 0.19 & 16.13 & 0.24 & 0.15 & 38.31 & 105.92 & 413263.02 \\
$\Phi_{\text {rc }}$ & - & 0.02 & 4.41 & 0.06 & 0.09 & 16.25 & 16.65 & 42711.12 \\
\hline
\end{tabular}

${ }^{\dagger}$ : significant at $5 \%$ probability by the $\mathrm{F}$ test, respectively; SV: source of variation; GCA: general combining ability; SCA: specific combining ability; $Ф$ gc, Фsc and $Ф$ rc: quadratic components of GCA, SCA and reciprocal effects, respectively.

Table 3. Estimates of general combining ability (GCA) and specific combining ability (SCA) obtained by diallel analysis for the traits plant height $(\mathrm{PH})$, stem diameter (SD), canopy projection between rows (CPB), canopy projection on the row (CPR), mass of one hundred grains (MHG), and grain yield (GY) in Jatropha

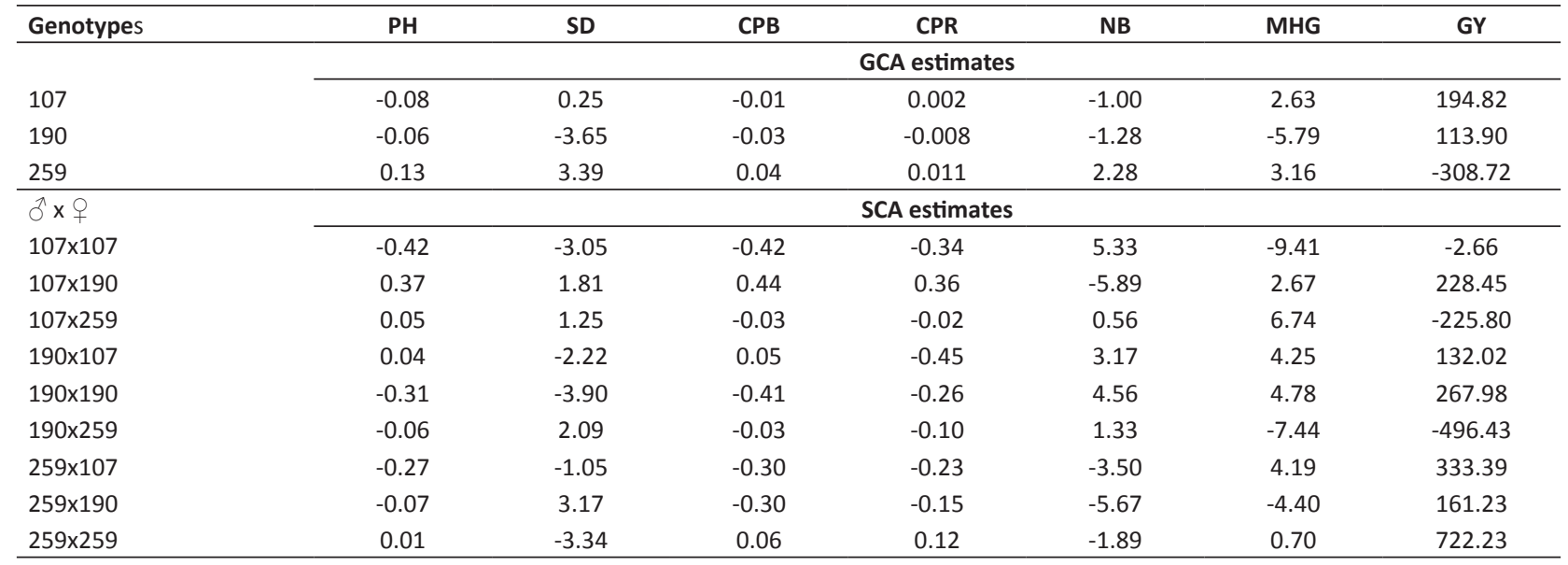


improve the population for these traits (genetic dominance and divergence). Moreover, reciprocal recurrent selection should be used to improve the intrapopulational hybrids.

Genotypes 107 and 190 presented positive GCA estimates for GY, and negative estimates for PH (Table 3), and can be considered good alleles donor to increase GY and reduce the size of Jatropha plants, which are two of the main objectives of the breeding program of this culture. Genotype 259 stood out with positive GCA estimates for all traits, except for GY, whose value was negative. GCA estimates provide information on the concentration of predominantly additive genes, and their effects allowed the identification of parents to be used in the obtainment of the population for selection. By analyzing these estimates, the favorable alleles for the evaluated traits are dispersed among the parents, and some reciprocal recurrent selection cycles may be necessary.

Another strategy to be used in the populations is the indirect selection, due to high estimates of $\mathrm{R}^{2}$ and Ac for all traits. Similar results were reported by Santana et al. (2013), who identified two genotypes with favorable alleles for six and four of the eight evaluated traits in diallel crosses of Jatropha. Moreover, Biabani et al. (2012) obtained GCA estimates that allowed identifying a parent effective for vegetative traits ( $\mathrm{PH}, \mathrm{SD}$, and number of leaves), probably due to the high genotypic correlation between them.

SCA refers to the deviation of the hybrid's performance in relation to what would be expected based on the GCA of their parents. The SCA effects suggest the presence of non-additive interactions resulting from allelic complementation between the parents, enabling the improvement in the estimate of the genetic gain by exploring the heterosis with the use of different crosses. However, by observing the four most promising crosses, based on GY, two of them are derivative

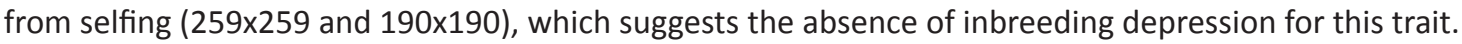

The crosses $259 \times 107$ and 107×190 also proved to be promising for the obtainment of populations based on SCA estimates for GY. These results were expected, since Rosado et al. (2010) had already observed genetic diversity at molecular level between these genotypes, which were clustered separately. The conduction of segregating populations from the cross $259 \times 107$ can be a favorable strategy for Jatropha breeding, since it enables the selection of genotypes of small size, with high grain yield, and which are resistant to powdery mildew, a disease that frequently occurs in the Brazilian Savanna. In addition, this cross combines parents with high GCA estimates for all traits, making it easier the selection of superior populations.

\section{Comparison of means}

Plant height is an important trait in the choice of the most appropriate spatial arrangement for planting, since Jatropha can exceed $5 \mathrm{~m}$ height. Thus, the breeder's efforts focus on selecting plants with small size for easier harvesting. Therefore, the selfings $107 \times 107$ and 190x190 were the most promising for $\mathrm{PH}$ reduction. Moreover, the hybrid formed by crossing the parents 107 and 190 and the selfings presented high mean for GY by the Scott-Knott test; thus, they formed the cluster with high GY (Table 4). Teodoro et al. (2016) observed that PH presents negative cause-effect relation with GY, suggesting that self-pollination of these genotypes may have contributed to the increase in the frequency of favorable alleles for the increment of $\mathrm{GY}$ and to the reduction of the size.

Table 4. Mean values for the traits plant height (PH), stem diameter (SD), canopy projection between rows (CPB), canopy projection on the row (CPR), mass of one hundred grains (MHG), and grain yield (GY) evaluated in nine Jatropha genotypes

\begin{tabular}{lcccccccccccccc}
\hline Genotypes & PH & & SD & & CPB & & CPR & & NB & & MHG & GY \\
\hline $107 \times 107$ & 1.72 & e & 71.54 & c & 1.97 & b & 1.83 & b & 27.87 & a & 61.44 & d & 1286.94 & a \\
$107 \times 190$ & 2.90 & a & 72.95 & c & 3.16 & a & 2.33 & a & 17.74 & b & 67.07 & c & 1451.12 & a \\
$107 \times 259$ & 2.32 & c & 76.22 & b & 2.12 & b & 1.87 & b & 24.80 & a & 79.49 & a & 670.63 & b \\
$190 \times 107$ & 2.63 & b & 75.26 & b & 2.95 & a & 2.38 & a & 15.73 & b & 63.76 & d & 1556.09 & a \\
$190 \times 190$ & 2.16 & d & 71.08 & c & 2.14 & b & 1.92 & b & 19.67 & b & 61.67 & d & 1432.44 & a \\
$190 \times 259$ & 2.36 & c & 83.22 & a & 2.23 & b & 1.89 & b & 21.33 & a & 69.36 & c & 588.52 & b \\
$259 \times 107$ & 2.77 & a & 79.98 & a & 2.93 & a & 2.29 & a & 23.07 & a & 73.86 & b & 1067.66 & a \\
$259 \times 190$ & 2.63 & b & 76.01 & b & 2.91 & a & 2.30 & a & 25.54 & a & 68.15 & c & 239.48 & c \\
$259 \times 259$ & 2.79 & a & 82.08 & a & 3.06 & a & 2.37 & a & 22.47 & a & 74.38 & b & 1093.51 & a \\
\hline
\end{tabular}

Means followed by the same letter in the same column do not differ by the Scott- Knott test. 


\section{PE Teodoro et al.}

SD, MHG and CPB have positive cause-effect relation with GY (Teodoro et al. 2016). Thus, indirect selection based on these traits can be carried out with the cross $259 \times 107$, which was also present in the cluster of higher GY. Also, as previously stated, the genotypes obtained from this cross presented small size, resistance to powdery mildew, and high grain yield. The crosses 190×107 and 107×190 may also be considered promising for the obtainment of superior populations, since they had high means for GY.

Therefore, by observing the cluster of genotypes with higher GY, almost all of the genotypes come from crosses with genotypes of high GCA for this trait (107 and 190), which reinforces the need of including these genotypes in future recurrent selection cycles for the obtainment of populations. Other relevant information for Jatropha breeding program was the high GY obtained by crosses derivative from selfings, which indicates the absence of inbreeding depression for this trait in Jatropha. However, this trait must be evaluated during the advancement of selfing generations before generalizing these results.

Therefore, since parents were chosen by molecular diversity previously reported (Rosado et al. 2010, Bhering et al. 2015), and based on all the results found in this study, the next step in the Brazilian jatropha breeding is to select superior individuals formed by the crosses $190 \times 107,107 \times 190$ and 259x107, and use them for the next breeding cycle, aiming to improve grain yield and reduce plant height.

\section{REFERENCES}

Bhering LL, Barrera CF, Ortega D, Laviola BG, Alves AA, Rosado TB and Cruz CD (2013) Differential response of Jatropha genotypes to different selection methods indicates that combined selection is more suited than other methods for rapid improvement of the species. Industrial Crops and Products 41: 260-265.

Bhering LL, Peixoto LA, Leite NLSF and Laviola BG (2015) Molecular analysis reveals new strategy for data collection in order to explore variability in Jatropha. Industrial Crops and Products 74: 898-902.

Biabani A, Rafii M, Saleh G, Shabanimofrad M and Latif M (2012) Combining ability analysis and evaluation of heterosis in Jatropha curcas (L). Australian Journal of Crop Science 6: 1030-1036.

Borges CV, Ferreira FM, Rocha RB, Santos AR and Laviola BG (2014) Productive capacity and genetic progress of physic nut. Ciencia Rural 44: 64-70

Cruz CD (2013) GENES - a software package for analysis in experimental statistics and quantitative genetics. Acta Scientiarum Agronomy 35: 271-276.

Cruz CD, Regazzi AJ and Carneiro PCS (2012) Modelos biométricos aplicados ao melhoramento genético. Editora UFV, Viçosa, 514p.

Griffing B (1956) Concept of general and specific combining ability in relation to diallel crossing systems. Australian Journal of Biological Sciences 9: 463-93.

Islam A, Anuar N, Yaakob Z, Ghani JA and Osman M (2013) Combining ability for germination traits in Jatropha curcas L. The Scientific World Journal 13: 1-6.

Kumar A and Sharma S (2008) An evaluation of multipurpose oil seed crop for industrial uses (Jatropha curcas L.): a review. Industrial crops and products 28 : 1-10.

Laosatit K, Mokrong N, Tanya P and Srinives P (2017). Overcoming crossing barriers between jatropha (Jatropha curcas L.) and castor bean
(Ricinus communis L.) Crop Breeding and Applied Biotechnology 17: $164-167$.

Laviola BG, Alves AA, Gurgel FdL, Rosado TB, Costa RD and Rocha RB (2012a) Estimate of genetic parameters and predicted gains with early selection of physic nut families. Ciência e Agrotecnologia 36: 163-70

Laviola BG, Alves AA, Gurgel FL, Rosado TB, Rocha RB and Albrecht JC (2012b) Estimates of genetic parameters for physic nut traits based in the germplasm two years evaluation. Ciência Rural 42: 429-435

Laviola BG, Oliveira AMC, Bhering LL, Alves AA, Rocha RB and Gomes BEL (2013) Estimates of repeatability coefficients and selection gains in Jatropha indicate that higher cumulative genetic gains can be obtained by relaxing the degree of certainty in predicting the best families. Industrial Crops and Products 51: 70-76

Ong H, Silitonga A, Masjuki H, Mahlia T, Chong W and Boosroh M (2013) Production and comparative fuel properties of biodiesel from nonedible oils: Jatropha curcas, Sterculia foetida and Ceiba. Energy Conversion and Management 73: 245-255.

Resende MVD and Duarte JB (2007) Precisão e controle de qualidade em experimentos de avaliação de cultivares. Pesquisa Agropecuária Tropical 37: 182-194.

Ramos HCC, Pereira MG, Viana AP, Luz LN, Cardoso DL and Ferreguetti GA (2014) Combined selection in backcross population of papaya (Carica papaya L.) by the mixed model methodology. American Journal of Plant Sciences 5: 2973-2983.

Rosado TB, Laviola BG, Faria DA, Pappas MR, Bhering LL and Quirino B (2010) Molecular markers reveal limited genetic diversity in a large germplasm collection of the biofuel crop L. in Brazil. Crop Science 50: $2372-82$

Santana UA, Carvalho Filho JLS, Blank AF and Silva-Mann R (2013) Combining ability and genetic parameters of physic nut genotypes for morphoagronomic traits. Pesquisa Agropecuaria Brasileira 48: 1149-1156. 
Spinelli VM, Dias LAS, Rocha RB and Resende MDV (2014) Yield performance of half-sib families of physic nut (Jatropha curcas L.). Crop Breeding and Applied Biotechnology 14: 49-53.

Spinelli VM, Dias LAS, Rocha RB and Resende MDV (2015) Estimates of genetic parameters with selection within and between half-sib families of Jatropha curcas L. Industrial Crops and Products 69:
355-61.

Teodoro PE, Costa RD, Rocha RB and Laviola BG (2016) Contribution of agronomic traits for grain yield in physic nut. Bragantia 75: 51-6

Wen M, Wang H, Xia Z, Zou M, Lu C and Wang W (2010) Developmenrt of EST-SSR and genomic-SSR markers to assess genetic diversity in Jatropha curcas L. BMC Researches Notes 3: 1-5 